\title{
The Localization Design of Jing-Chu Context in the Renovation and Renewal of Urban Public Landscape
}

\author{
Yuhui Yuan ${ }^{1, *}$ Xiaoyun $\mathrm{Ni}^{1}$ \\ ${ }^{1}$ College of Art and Design, Wuhan Textile University, Wuhan, Hubei 430070, China \\ *Corresponding author. Email: 105189368@qq.com
}

\begin{abstract}
Urban public landscape design is an important part of environment design, and it is the carrier of current urban form. At present, with the diversified development of society, more and more landscape designers blindly pursue "modern" style, losing the characteristics of traditional context and lacking deep-seated cultural emotion expressions. Taking the urban public landscape as a carrier, through sorting out the Jing-Chu context and systematically analyzing the localization design of urban landscape, the purpose of this research is to build and perfect the missing regional cultural texture, which has certain theoretical value for the research of Jing-Chu cultural theory system and the construction of urban public landscape with regional characteristics.
\end{abstract}

Keywords: Localization design, Jing-Chu context, Renovation and renewal, Urban public landscape.

\section{INTRODUCTION}

In recent years, many cities in China have begun to propose the renovation goals of urban landscape space. Taking Wuhan, the "city of a thousand lakes" in central China, as an example, the government has planned a riverside landscape renovation method with local characteristics of Wuhan through its unique regional environment and thought of regional culture and history, and improved the current spatial layout of the city. At present, how to interact and integrate the urban cultural context and modern landscape design has become an urgent and important project.

\section{INTERPRETATION OF THE CONCEPT OF "LOCALIZATION"}

Localization design is a design form that integrates local traditional culture, lifestyle, folk customs and artistic characteristics, which exists in all aspects of design. With the constant change of the times, if China's urban public landscape wants to take a place in the world, it's necessary to formulate a unique localization landscape plan that belongs to the local area. At the same time, local enterprises and the broad public must also regard themselves as a part of the prosperous urban landscape culture, fully understanding and disseminating traditional regional cultural characteristics.

In the local design concept, the performance of public landscape design is mainly reflected in public landscape materials, architectural styles, and design techniques. The use of local materials can not only reduce consumption, but also promote the development of local enterprises. Through the analysis of local people's living habits, ethnic customs, and climatic conditions, it can satisfy people's living habits. Taking the design of the Suzhou Museum as an example, its architectural image works in concert with the local environment and fully demonstrates the local artistic heritage and cultural context. In Japan, geographical factors cause frequent earthquakes. Designers find that the wooden structure has great ductility, earthquake resistance, etc., so wooden structures are often used in the building structure to protect the safety of residents to the greatest extent and reduce losses. 


\section{ANALYSIS ON THE STATUS QUO OF URBAN PUBLIC LANDSCAPE IN JING-CHU REGION}

\subsection{An Observation and Study on the Context and Historical Origin of Jing- Chu}

The Jing-Chu context has a profound historical and cultural background. The ancestors of Chu created the Chu culture in the Yangtze river basin of ancient Chinese civilization by "driving simple vehicles and wearing tattered clothes to exploit mountains and forests". The development of Chu culture can be divided into four key periods: the germination period, the development period, the peak period and the transformation period, and each period breeds, continues and inherits the distinctive symbol characteristics of the decorative context for later generations. [1]

The year $740 \mathrm{BC}$ was the germination period of $\mathrm{Chu}$ culture. The period from the founding of the Chu in Danyang to King Zhou Pingwang was the germination period of Jing-Chu culture. During this period, the clever Chu people got rid of the primitive social tribal system that was backward at that time by virtue of their own intelligence and wisdom, and transformed into a higher-level social system of feudal slave. During this period, the people of Chu created their own characteristic culture - Jing-Chu culture on the basis of Huaxia culture. The Jing-Chu culture was mainly developed in the cultural aspects of pottery and bronze ware. On this basis, it continued to be inclusive with the early Huaxia culture, which made Jing-Chu culture show more unique charm, such as forging ahead, not sticking to law and discipline rite, and love for creating something unconventional or unorthodox and other cultural characteristics. The continuous expansion of the power of Chu State also laid a solid foundation for the development of Jing-Chu culture, forming a colorful and all-encompassing Jing-Chu culture.

The Spring and Autumn Period is an important stage of the development of Chu culture, and its cultural heritage and cultural form gradually matured. For example, the copper ware Zenghouyi Chime (see "Figure 1") was not only an important attestation to the development of Chu's music and culture, it also represented the supreme power of the state, laying a solid foundation for the emergence of Chu's shovel-shaped tombac.

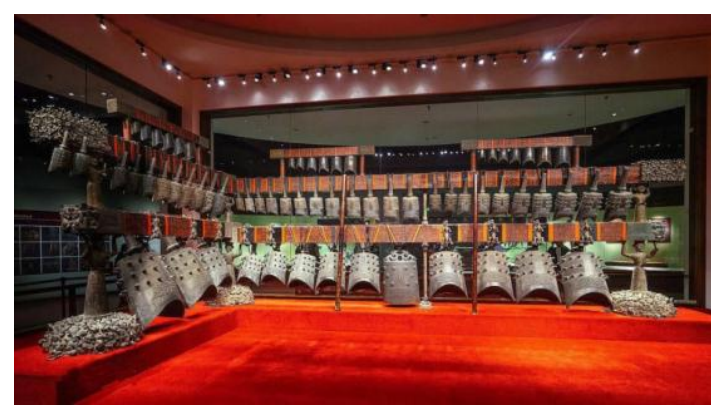

Figure 1 The chime of Zenghouyi in Hubei Provincial Museum.

The Warring States Period was the peak period of the development of Chu culture. The politics, system and economy of Chu State were all filled with the unique flavor of $\mathrm{Chu}$ culture. The environmental design of Chu culture was mainly manifested in the construction of Yingdu of Chu State. Its site selection and planning had already established a mature system. The imperial palace had an independent area, there was a moat outside the palace, there were observation towers and palace walls inside the palace, and the defense and security parts were also greatly improved. At the same time, the carving patterns of handicrafts during the Warring States Period made great breakthroughs, which also reflected the development context of Chu culture at that time, and played an important role in inheriting the decorative modeling of Chu-character lacquerware landscape and the application of Chu culture color resources in the future. (see "Figure 2")

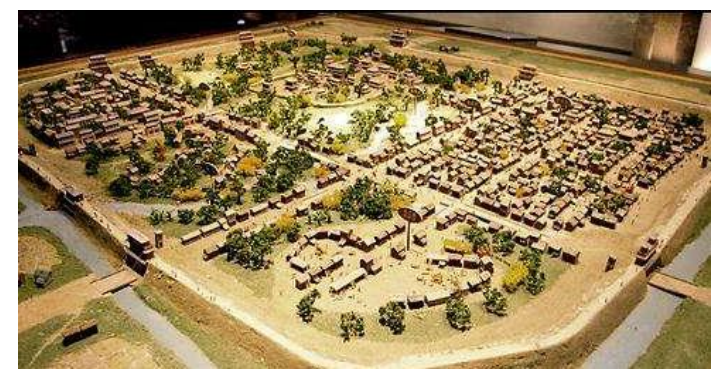

Figure 2 The overall model of "Chu Kingdom South City" is restored in Hubei Provincial Museum.

The period between the Qin and Han Dynasties was the transformation period of Chu culture. Since the first emperor of Qin burned and robbed the Chu culture after destroying the $\mathrm{Chu}$ State, the development of $\mathrm{Chu}$ culture was destructively hindered. However, the soul of Chu culture and the inheritance of national culture had been deeply rooted in the hearts of Chu people, and it caused 
many descendants of Chu State to have a deeper development of the Chu culture context.

\subsection{The Status Quo of Urban Public Landscape in Jing-Chu Region}

Jing-Chu culture is a unique local culture in Hubei. In ancient times, the scope of the concept of "Jing-Chu" was roughly based on the administrative divisions of today's Hubei Province. Therefore, Hubei people often refer to the province as the "Jingchu Land". The designer takes the Jingzhou ancient city in Jingzhou City, Hubei Province, as an example. The ancient city wall of Jingzhou was founded in the Spring and Autumn Period and the Warring States Period, and has been baptized by many generations. Most of the existing buildings are from the late Ming and early Qing dynasties. By investigating the Jingzhou ancient city in the JingChu region, the designer finds the following current situation, that is, the ancient remains of historical buildings and the protection of historical blocks are worrying. Many buildings along the street in the historical blocks are built randomly, without reasonable design and planning, and the new buildings are extremely inconsistent with the style and feature of the ancient city, which seriously affects the surrounding environment of the historical buildings. Many new buildings are incompatible with the surrounding landforms in their colors, styles, materials, etc. Some small remodeled houses block the overall appearance of the historical houses, and a large number of modern buildings have damaged the historical blocks to a certain extent. ("Figure 3")

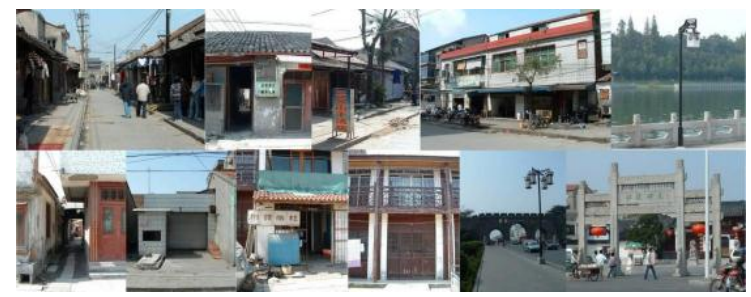

Figure 3 The actual scene of "Sanyi Street" in the ancient city of Jingzhou.

The functional layout of buildings in the Jingzhou ancient city and the proportion of land use planning are seriously unbalanced, and the planning and positioning of the land use of the ancient city doesn't conform to the norms. For example, the Jingzhou ancient city in Hubei is planned to occupy an area of 4.5 square kilometers, but the land of administrative agencies and public institutions accounts for about $20 \%$ of the entire land, occupying a relatively large area for administration, education, and medical care, so that the ancient city's core functional areas have not been effectively utilized. Although Jingzhou has unique advantages in tourism resources, it can't be fully utilized, which restricts the economic development of Jingzhou under certain conditions.

The ecological system and human settlement environment of Jingzhou ancient city are extremely poor. The Jingzhou ancient city is too densely populated, with a population of about 100,000. Due to the excessive load of the old city, its infrastructure such as transportation, buildings, roads, and firefighting is overwhelmed. Excessive population water consumption has led to inefficient drainage systems and intricate pipelines in many historical buildings. The lakes and wetlands in the ancient city are largely occupied. When the rainy season comes, they fail to play the role of flood prevention and storage and water conservation, resulting in frequent waterlogging and floods in the city. The drainage system in the south and west of the ancient city has not been discharged into the moat through sewage treatment, resulting in the extremely poor water environment in the region, the rebirth of weeds rivers, the serious water pollution, and the extremely bad living environment.

\subsection{The Needs of People in Jing-Chu Region for Urban Public Landscape}

Taking the public landscapes of representative cities in the Jing-Chu region, such as Wuhan, Jingzhou, and Yichang as the survey objects, after conducting horizontal and vertical field research and data model analysis, the designer makes an indepth study on the impact of the urban public landscape with Jing-Chu context feature on the psychological and physiological activities of citizens, and summarizes excellent cases and existing problems, taking solving these problems as the starting point of the project.[2]

Through the designer's interview and investigation, it's found that people in Jing-Chu region have the following three main requirements for urban public landscape: First of all, many people call for more construction or renovation of urban public landscapes that conform to the historical culture of Jing-Chu region, and reflect the cultural characteristics of the region. For example, in some designs, it's hoped that designers can add the Jing-Chu culture's typical opening spirit of "pacifying the barbarian to belong to Huaxia culture", the innovative spirit of "making a great 
coup", the patriotic spirit of "being deeply rooted and unable to migrate" and the harmony and union spirit that "military forces are to be used only for the maintenance of peace and order". Combining localized elements with public landscape design is the strongest appeal of the broad public for urban public landscapes. Some young people think that while constructing urban public landscapes, attention should be paid to the division of public landscape types and functions. For example, the types of some parks, squares, and leisure activity centers are not clear enough to highlight the theme of the region. For another example, many parks and squares only have stone chairs, light strips, vegetation, etc., and their design content form is too simple and the function division is not clear, resulting in reduced passenger flow volume and extremely low utilization of public space. [3]Finally, in the renovation and renewal of Jing-Chu culture, the most important thing is to highlight the rational use of Jing-Chu cultural elements, further clarify the evolution and outstanding characteristics of the Jing-Chu school and understand the deep cultural connotation of the Jing-Chu region through the study of the Jing-Chu context. [4]

\subsection{Problems Existing in the Public Landscape Renovation of Jing-Chu Context}

With the rapid development of urbanization in Jing-Chu region, how to renovate and renew the local design of urban public landscape has become the main problem faced by designers, which requires designers to reflect the characteristics of the urban public landscape against the background of Jing-Chu context, as well as the design method to combine the public landscape with the regional characteristics of the city and the background culture to handle the relationship among protection, renovation and renewal.

Based on the context of Jingchu context and starting from the composition of urban public landscapes, it's necessary to conduct in-depth research and analysis of various landscape spaces such as urban parks, squares and streets, and waterfront landscape belts, identify the landscape elements that need to be renovated and preserved in the renewal design, and determine the design methods and strategies of landscape structure planning, landscape planning, scenic spot layout, and landscape system planning. The specific problems of the urban public landscape in Jing-Chu region include: First, inappropriate design positioning, ignoring the actual social use function value; second, poor publicness and openness of the designed area, failing to enable the public to feel the transformation results of the public landscape environment renovation; third, losing characteristics and individuality, lacking in-depth context and expression of local design concepts; fourth, unscientific and blind design, causing varying degrees of damage to historical resources and the natural environment.[5]

\section{THE EXPRESSION OF JING-CHU CONTEXT IN LOCAL DESIGN}

At present, many cities have begun the reconstruction of construction land and old cities, and the local culture is gradually being devoured by cities and buildings. In Hubei, the inheritance and charm of some Jing-Chu cultures is gradually being diluted by the rising modern style, and the crisis of "many cities with the same appearance" has gradually spread. Faced with the subject of how to reshape the public landscape style of Jing-Chu city, the main key point is to explore the "source" of the architectural style of Jing-Chu culture.

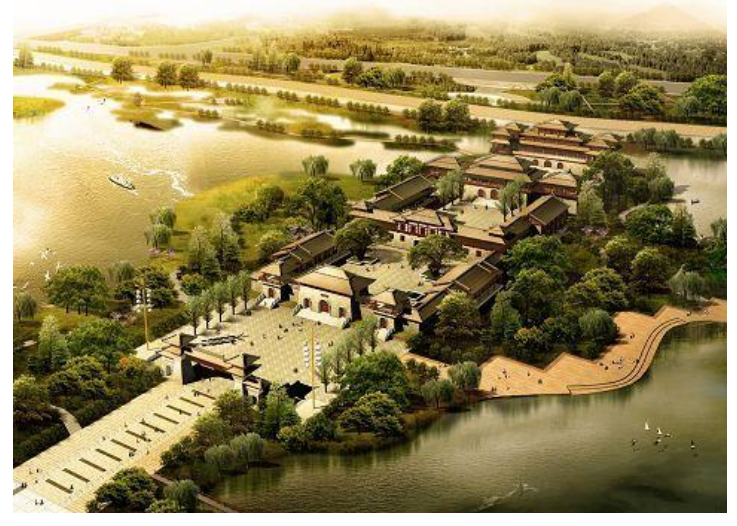

Figure 4 Restored image of "Zhang Huatai" of Chu Li Palace.

By referring to data and literature, the designer can summarize the aesthetic characteristics of JingChu cultural buildings into ten points: linear, harmonious, magnificent, kinetic, borrowing, ethereal, hazy, exceedingly gorgeous, weird, and outstandingly beautiful. These characteristics are just the portrayal of the particular Chu people's unrestrained soul, and the true expression of Chu people's harmony with nature and the unity with the heaven and earth. ("Figure 4")

For example, in the architectural design of Chu people, various lines were cleverly combined to 
create rich and colorful architectural works. In the architecture of Chu State, for example, building eaves and decorative components used linear beauty to highlight the architectural style characteristics of the beauty of the building. Secondly, the ethereal beauty of architecture was mainly manifested in the Jing-Chu contextual architecture in the form of spatial changes. The pavilions built by Chu State were all open-ended, and they were closely related to nature. The space inside and outside the pavilion also penetrated each other, reflecting the ideological principles of advocating nature of $\mathrm{Chu}$ people. The public landscape space performance of Chu State was full of unusually strong vitality and powerful sports spirit. For example, in the design of buildings, Chu people always strived for design techniques from static to dynamic, but the still quiet behavior contained a lively and enthusiastic vitality. From the perspective of structural law, it often dared to break the rigid symmetrical balance while pursuing an overall upward dynamic balance. This rule embodied the structure of dynamic beauty, and was the spiritual dynamic beauty of Chu people free from traditional constraints.

\section{THE DESIGN AND RENOVATION OF URBAN PUBLIC LANDSCAPE IN JING-CHU CONTEXT}

The designer conducts in-depth research on the urban background, historical origin, and urban image of the Jing-Chu region (such as Wuhan, Yichang, Jingzhou, etc.) in various periods, and combines multiple research methods to analyze the urban public landscape behavior, sorting out and extracting the design, value, symbol and expression with Jing-Chu characteristics.

\subsection{The Embodiment of the Reformation of Element Symbols in Local Design}

Modern society is in a state of high frequency renewal. The integration of Jing-Chu context and urban environmental landscape must put forth new ideas in expression, in addition, the local culture needs to keep up with the pace of the times and create element symbols with new social significance. [6]

In the process of exploring the Jing-Chu context, designers need to start with the shapes, patterns, colors, and materials of historical relics such as bronzes, chimes and pottery unearthed in Jingzhou and other regions, find the elements of Jing-Chu culture and the symbolic language, and summarize some artistic expression techniques with Jing-Chu characteristics, so that Jing-Chu culture and symbolic language can be embodied in the urban public landscape design, thereby making the architecture of Jing-Chu region more charming. By this way, it can reflect the local cultural customs and aesthetic concepts of the local people from the side, so that the image of Jing-Chu land with cultural heritage is more well-rounded. [7] In the architectural design of Wuhan, Hubei Province, there are many cases making use of element symbols. [8] The Hongshan Auditorium, located in Hongshan District, uses a variety of Chu cultural elements in the building: For example, in the form of bronze chimes and patterns of Chu clothing, the overall appearance resembles the image of a soaring phoenix, which contains the intent of "凤" advocated by the people of Chu.

\subsection{Paying Attention to the Value Idea of Regional Traditional Culture}

In terms of design concept, as a designer, one must pay attention to the principle of harmonious coexistence between man and nature, the use of the original texture of materials, the formal beauty of the expression of public landscape architecture, and the deeper expression of traditional cultural concepts. The urban public landscape reorganizes the historical context and combines it with contemporary new culture to get a virtuous circle. In today's increasingly developing hub of the times, it's necessary to extract local cultural symbols from historical contexts and blend them with modern new cultures, and rationally use design concepts to form the social value and aesthetic value of the new era and try to make the regional cultural connotation consistent with contemporary design concepts.[9]

\subsection{Coordination and Unification of Ecologically Healthy Urban Public Landscape and Local Design}

In modern public landscape design, the design concept of ecologically healthy city and local design are particularly important for coordination and unification. In the continuous renewal of urban public landscapes, attention should be paid to the relationship between public landscape renewal and green and healthy ecological landscapes. As a communication platform between man and nature, urban landscape is an important place for people to live and survive. As people pay more attention to 
the ecological environment, urban public landscapes have become an important part of the human settlement environment. Creating a comfortable, healthy, green and ecological urban landscape space has become a focused issue of concern. [10]

Healthy urban landscape design is mainly divided into two aspects: The first is to combine different landscape elements to provide a public space in contact with nature, meet people's material and spiritual needs, release people's mental pressure, and provide rescue sites for emergencies; the second is to create a healthy urban landscape atmosphere, encourage people to travel and exercise, and people's lifestyles. Promoting the health of urban population and improving the physical fitness of residents, a good urban landscape space provides a place for people to play, rest, exercise, etc. To this end, designers must incorporate the design concept of an ecologically healthy city while carrying out local design, such as creating a series of rainwater gardens and wetland parks in the Jing-Chu region with local Chu culture.

\section{CONCLUSION}

By discussing the thoughts and concepts of landscape design with Jing-Chu context in China, this project analyzes and summarizes the influencing factors and characteristics of the urban public landscape of Jing-Chu context, explores people's beliefs, historical relics, lifestyles and folk art under historical changes, and introduces the indepth study of culture and soul from the discussion of forms. By analyzing Jing-Chu's history, culture and development of the times, vertically, this project makes a strong reference and support to the historically precipitated landscape culture; horizontally, it fully considers the site characteristics, respects its original characteristics and reflects the local regional culture to create a new culture of urban regional landscape and have a dialogue with the landscape design of the entire era. This has certain practical guiding significance for the construction of public landscape of Jing-Chu regional culture and the design and development of related urban regional landscape context.

\section{AUTHORS' CONTRIBUTIONS}

Yuhui Yuan wrote the paper and analyzed the theory and design; Xiaoyun $\mathrm{Ni}$ conducted background research and data collection for the paper.

\section{REFERENCES}

[1] Zhang Cong. The landscape decoration planning of Jingzhou ancient city and the application of Chu culture context[D]; "Journal of Central China Architecture".2010. ( in Chinese )

[2] Song Yijun. The application of Jingchu culture in the architectural design of Wuhan [D]. Master's degree thesis of Wuhan University of Technology. 2015.(in Chinese)

[3] Yu Kongjian. The Art of Survival: Positioning Contemporary Landscape Design [M]. Beijing: China Building Industry Press. 2006 edition. (in Chinese)

[4] Zhang Tong. Jing-Chu Context [M]. Wuhan: Hubei People's Publishing House. 2013. (in Chinese)

[5] Liu Binyi. Modern Landscape Planning and Design [M]. Nanjing: Southeast University Press. 2002. (in Chinese)

[6] He Chenyue, Zhao Yuxuan, Wang Wenchen, et al. Application of Jingchu Culture in Modern Landscape[J]. Green Technology (13): 4.2020.(in Chinese)

[7] Song Qixing. Strengthen the application of regional culture in garden landscape design: Taking Wuhan as an example[J]. Modern Horticulture, 2017.(in Chinese)

[8] Wu Wei, Zou Jiaxi. Research on the Humanistic Landscape of Wuhan Tourist Destinations under the Background of Cultural and Tourism Integration [J]. Anhui Architecture, 2021.(in Chinese)

[9] Zhang Junyi. On the landscape design strategy of pedestrian street in cultural scenic spot based on Jingchu culture [J]. Popular Literature and Art, 2020.(in Chinese)

[10] Edited by Claire Cooper Marcus, etc. Place of Humanity - Design Guidelines of Urban Open Space [M]. Beijing: China Building Industry Press. 2001. (in Chinese) 